\title{
A Review of Soviet-Style Basic Teaching in Sculpture Teaching in Chinese Colleges
}

\author{
Bo Qin ${ }^{1, *}$ \\ ${ }^{1}$ Jingdezhen Ceramic Institute, Jingdezhen, Jiangxi 333403, China \\ *Corresponding author. Email: $381091841 @ q q . c o m$

\begin{abstract}
Compared with French-style teaching, the Soviet mode of sculpture teaching in China's colleges has the following characteristics. First, there was a unified teaching mode in the Soviet Union that was easy to be introduced to China; secondly, the introduction and promotion of Soviet-style sculpture teaching has a strong color of government act; third, with two introduction ways of sending students to the Soviet Union and inviting experts from it, China learnt from the Soviet mode in a comprehensive and systematic manner; fourth, the time span of learning is large, from the 1950s to the beginning of this century. The introduction of the Soviet mode of sculpture teaching enabled Chinese art schools to have a complete and effective teaching system, under which most sculptors in New China were cultivated.
\end{abstract}

Keywords: academy of fine arts, sculpture, teaching

\section{INTRODUCTION}

At the beginning of the 20th century, China began to establish its own modern education system modeled on that of the West, and art colleges were introduced to China during this period. Sculpture, as one of the representatives of Western culture, was valued by people of vision for its obvious role in education and beautification of the city. Therefore, both art academies and art schools in the Republic of China had the same major of sculpture. Most of the teachers have the background of studying abroad in Des Beaux-arts de Paris, which forms the tradition of French-style sculpture in Chinese sculpture teaching. Due to the political instability and wars at that time, the sculpture profession did not develop on a large scale. After the founding of new China, a comprehensive study of the Soviet Union began, and education is no exception. China began to learn from the Soviet Union in terms of sculpture teaching in an all-round way, and was promoted to fine arts colleges all over the country, forming the Soviet school of sculpture teaching in Chinese colleges, which continues to this day.

\section{TWO IMPORTANT PERIODS OF LEARNING} SOVIET SCULPTURE TEACHING

The introduction and study of Soviet sculpture in China were mainly in two periods. At the beginning of the founding of the People's Republic of China, influenced by the Soviet Union, the government attached great importance to the development of sculpture industry. In order to train qualified teachers and creative talents for socialist literature and art, in the early 1950s, Qian Shaowu, Dong Zuyi and Wang Keqing were selected to study in the Sculpture Department of Ilya Repin Leningrad Institute for Painting, Sculpture and Architecture. Then, the introduction way of inviting experts was adopted. In 1956, the Ministry of Culture invited Kremlindukhov, a Soviet sculptor, to hold a research class in the Central Academy of Fine Arts, with a study duration of 2 years. The students came from young and middle-aged teachers selected by various fine arts institutes throughout the country. The teaching condensed the whole content of six-year Soviet sculpture teaching, and demonstrated the systematism and completeness of the Soviet sculpture teaching. After graduation, the students of the training class returned to their teaching posts and became the backbone of sculpture teaching in their respective fine arts colleges, promoting the Soviet sculpture teaching system to the whole country. Most of them, for example, Yang Meiying of LuXun Academy of Fine Arts, Shen Wenqiang of Zhejiang Academy of Arts, Liu Zhengde of Hubei Institute of Fine Arts, Guan Weixian of Guangzhou Academy of Fine Arts, Ma Gaihu of Xi'an Academy of Fine Arts, Wang Guanyi of Sichuan Fine Arts Institute, etc., later served as the dean or director of the sculpture department of their colleges.

In the 1980s, relations between China and the Soviet Union was gradually normalized. Out of admiration for and insistence on the realistic tradition of fine arts academies, the Ministry of Culture and the Central Academy of Fine Arts once again sent students to study in the Soviet Union, studying oil painting, sculpture and fresco. Among them, Chen Ke, Zhang Wei and Zhou Simin studied in the Sculpture Department of Ilya Repin Leningrad Institute for 
Painting, Sculpture and Architecture. After graduation, they came back to China to engage in teaching and were responsible for the teaching (traditional Soviet Union) of the second studio of the Sculpture Department. In 2004, Chen Hui and Wei Erqiang, young teachers of Academy of Fine Arts of Tsinghua University, went to Ilya Repin Leningrad Institute for Painting, Sculpture and Architecture and Moscow State Academic Art Institute named after V.I. Surikov respectively as visiting scholars for one year. During this period, there were other art colleges and universities sending young teachers to study in Russia and self-financed students, which will not be listed here.

In 1996, at the invitation of the Ministry of Culture, Mr. Kubassov, professor of the Sculpture Department of Ilya Repin Leningrad Institute for Painting, Sculpture and Architecture, came to China to hold a high-level research class. The students were teachers from the sculpture departments of various fine arts colleges and sculptors from sculpture creation units, such as Li Xiangqun, Wang Hongliang, Wang Qiyue and Guo Jinghan. Later, Kubassov was invited to hold classes at Jilin University of the Arts.

Compared with the French academism tradition of sculpture, the influence of Soviet academies of fine arts on Chinese sculpture teaching has been long-term, extensive and deep, and will continue to exert influence on Chinese sculpture teaching for a long time to come.

\section{OVERVIEW OF SCULPTURE TEACHING LEARNING FROM SOVIET ACADEMIES OF FINE ARTS}

Through the introduction and learning of the Soviet Union's teaching mode of sculpture, China's sculpture teaching has formed a relatively complete system. Many sculptors cultivated under this teaching system have become the backbone of China's sculpture field. Ilya Repin Leningrad Institute for Painting, Sculpture and Architecture attaches great importance to the continuation of the tradition. The teaching of the sculpture Department is almost the same as that of international students in the 1950s. There are many articles and monographs on teaching in the Soviet Union (Russia). In the paper "Talking About Teaching Basic Courses of Sculpture from Ilya Repin Institute of Arts", Chen Hui, a teacher of Academy of Arts \& Design, Tsinghua University introduces the basic teaching of sculpture in Ilya Repin Leningrad Institute for Painting, Sculpture and Architecture as follows.

"The teaching arrangement of sculpture is basically:

- First semester of the first grade: head sketching in relief, relief copy, round head sketch, chest sketch. Second semester of first grade: human body sketch (1 meter high), dressed figure sketch (1 meter high).

- First semester of grade two: human body sketch, human body in relief. Second semester of grade two: animal sketching (horse), 2/3 human sketching.

- First semester of the third grade: double chest sketch, human body sketch in relief. Second semester of the third grade: dressed figures sketch, same-size human body sketch.

- First semester of the fourth grade: $2 / 3$ dressed human body sketch, three times hand and foot sketching, dressed human body sketch. Second semester of senior year: small graduation creation (same-size or above 1 meter) figure creation.

- First semester of the fifth grade: half body sketch with embossed clothes, etc., same-size human body sketch. The second semester of the fifth grade: same-size human body sketch.

- Sixth grade: graduation creation.

From grade one to grade five, there are three hours of sculpture each day, and one and a half hours of sketching each day. The creation class is arranged after class. Generally, there are two small drafts for the creation homework in one semester. The creation class covers character creation, portrait creation and architectural decoration (renderings are required). In the middle of the semester, there are also practical classes of stone, wood, copper casting and other materials."

\section{THE CHARACTERISTICS OF SOVIET SCULPTURE TEACHING}

The teaching of Soviet sculpture has three basic characteristics: systematicness, scientificity and practicality.

\section{A. Systematicness}

The Sculpture Department of Ilya Repin Leningrad Institute for Painting, Sculpture and Architecture adopts an academic system similar to the continuous study of bachelors-masters degrees. The curriculum from grade one to grade six is an organic whole with sufficient time and necessary repetition, which is convenient to give specific and targeted teaching requirements at different stages according to the characteristics of students' deepening understanding. Taking the head homework for example, in the first grade students are given a large number of assignments and a relatively short class period for each. In class, the focus was put on the study of basic knowledge and basic laws such as anatomy, structure and form, proportion and dynamics. By the third grade, the number of head assignments has 
decreased, but the amount of time spent on individual assignments has almost doubled. The aim is to give students enough time to devote to the characterization of the models and the deep understanding of the beauty of the models themselves, in addition to completing various problems to be solved in the lower grades, so as to achieve a vivid and lively artistic effect. Shaping, creating and sketching are carried out at the same time, which is conducive to the mutual connection and promotion between different courses.

\section{B. Scientificity}

Its scientificity is most obviously presented in the strict requirement of anatomical knowledge and the use of measuring tools. At the Ilya Repin Leningrad Institute for Painting, Sculpture and Architecture, anatomy is a required course for students. There are special anatomy classrooms and full-time anatomy teachers. The classroom has detailed anatomy teaching aids for learning and use, and there are strict examinations of anatomy completion. Students are required to know enough about anatomy to be able to write down the name and shape of each bone that makes up the skull. The use of calipers and hammers is a characteristic of Soviet teaching. According to Wang Hongliang, Mr. Kubasov once said in the senior research class, "The caliper is used to find the scale, and the lifting hammer is used to find the center of gravity. When I am away, the caliper and the lifting hammer are your teachers." Young teachers returning from the Soviet Union also emphasize the use of calipers and hammers in their teaching.

\section{Practicality}

Its practicality is not only reflected in that corresponding adjustments are made in the curriculum arrangement and teaching requirements for different stages of students' understanding, which have been discussed above. It is also reflected in the choice of teaching content. The emphasis on embossing and dressing teaching is much higher than that of Chinese art colleges and universities. Hands and feet are made separate projects for deep study. This is undoubtedly for the needs of students to create and engage in the work of environmental sculpture after graduation.

\section{INFLUENCE OF SOVIET TRADITION IN SCULPTURE TEACHING IN CHINESE COLLEGES}

From the 1950s, it became politically correct for Chinese art schools to study the Soviet Union, and Soviet realistic art was regarded as advanced and revolutionary art. In contrast, the Western academic classical art represented by France represents the aesthetic taste of the bourgeoisie and was regarded reactionary and backward. In this environment, the teaching of French-style sculpture gradually declined.
Through the promotion of students studying in the Soviet Union and the Soviet expert class, the Sovietstyle sculpture teaching has obtained the absolute status in the sculpture teaching in Chinese colleges. In the 1960s, when Sino-Soviet relations deteriorated, the state began to promote self-reliance in building socialism, and the direction of literature and art encouraged people to learn national traditions. Teachers and students majoring in sculpture went out to study and copy ancient Chinese sculpture, and folk artists were invited to teach folk colored sculptures in the academies of fine arts. This had a certain impact on the teaching of Soviet sculpture, but did not change it fundamentally.

After the Cultural Revolution, academies of fine arts resumed their enrollment, and they basically followed the Soviet-style sculpture teaching mode in the 1950s and 1960s. The course contents were slightly different, but basically the same as before. The course was mainly composed of sketch, clay sculpture and creation. The course is arranged in a progressive order, from easy parts to difficult ones: head, bust and human body; from small tasks to large ones: 1/2 human body, 2/3 human body and same-size human body; sketching is the main method. Copy courses are arranged as a transition between two courses. For example, the plaster copy course is set between the head sketch course and clay head course for the first grade and the human anatomy plaster copy before the clay human body course for the second grade. Some institutes set the course that lets a student choose dynamic, expressive technique by themselves on the basis of reference model in senior grade, for example, the course of "Imagist Hunam Body" in Luxun Academy of Fine Arts. Long term homework is given priority to. Before the clay body course, there is a quick sculpture course as an auxiliary course. The principle of realism is valued, requiring the homework to faithfully and correctly reflect the shape of the model proportion characteristics, structural relations and personality characteristics and to achieve unity of form and spirit. The arrangement of specialized courses in China's academies of fine arts is basically the same as that of the Sculpture Department of Ilya Repin Leningrad Institute for Painting, Sculpture and Architecture in the order from simplicity to difficulty. Yet there is a lack of repetition of learning cycles. In addition, the different courses are arranged vertically with no horizontal connection. Unlike the Sculpture Department of Ilya Repin Leningrad Institute for Painting, Sculpture and Architecture, the courses of head, bust and human body are repeated and cycled. The class time of embossment and garment grain also has greatly reduced compared with Ilya Repin Leningrad Institute for Painting, Sculpture and Architecture. The main reason is that the sculpture department of Chinese academies of fine arts adopts a four-year or five-year undergraduate system. In order to 
adapt to this, the curriculum arrangement has been adjusted.

The 1990s is a period of social and cultural transformation, with increasingly close international cultural contacts and exchanges. Influenced by Western artistic trends, some sculptors gradually changed their exploration and study of materials and language forms into an emphasis on the expression of ideas. They attempted to expand the traditional concept of sculpture and make sculpture develop in a direction of installation and visualization. The profound academic background of these sculptors, as well as the success of some Chinese artists in important exhibitions in the West, has had an impact on the teaching of sculpture. This kind of influence began to appear after 2000, when some academy of fine arts made corresponding teaching reform. For example, the Central Academy of Fine Art added a modern materials studio on the basis of the original ceramic and metal studios, with the purpose of introducing materials, concepts and other languages into the teaching system. However, except for the first studio, which is a continuation of the teaching tradition of the French style, other studios still follow the teaching model of the Soviet style. The direction of the studio is only evident in the courses of the fourth grade and graduation creations. The setting of new studio does not seem to have much impact on realistic basic teaching. The sculpture major of other academies of fine arts is basically the same as that of the Central Academy of Fine Art. No matter it implements grade system or studio system, its basic teaching still continues the tradition of Soviet-style teaching. The main reasons are as follows. On the one hand, the traditional concept is still strong, believing that realism is the foundation of sculpture. Due to the strong power of the Soviet tradition, the inertia will continue to play a role in a certain period of time in the future. On the other hand, because these art forms are still in the exploratory stage in teaching, the teaching system and qualified teaching staff have not yet formed. But the concept change of sculpture will inevitably lead to the change of the understanding of basic teaching, and the major change is only a matter of time.

\section{CONCLUSION}

With the introduction of the Soviet teaching mode, China's fine arts colleges and universities have established a complete and effective teaching system. Chinese sculptors have been cultivated in this system since the $1950 \mathrm{~s}$, making great contributions to the Chinese sculpture industry. After entering the 21st century, Soviet-style sculpture teaching is still playing an important role in the basic teaching of fine arts colleges. Mr. Qian Shaowu, the former director of the Sculpture Department of the Central Academy of Fine Art, who once studied in the Soviet Union and has been engaged in teaching for a long time, has a very pertinent summary of soviet-style sculpture teaching. "By copying the Soviet Union from all aspects, there appears to be an integrated approach from basic training to creative teaching. For example, in terms of basic training, the Soviet Union attached great importance to long-term operation, anatomical knowledge and comprehensive sketching, as well as shape, structure and proportion. In a word, it attached great importance to basic realistic techniques. We should say that this method of training contributes to the realistic foundation of the sculpture department. The weakness is a big step behind the education of artistic beauty, especially the emphasis on the spatial beauty of form, the most fundamental core of sculpture." 1 The weakness or even lack of art aesthetic education is a common problem in art education in Chinese colleges, which is reflected in the training objectives and curriculum setting of art colleges as well as the overall cultural quality of teachers and students. This cannot be all attributed to the Soviet-style teaching mode. However, it is certain that a large amount of technical and intellectual learning content in Soviet sculpture teaching occupies most of the time in and out of class, as a result of which students have no time to pay attention to the in-depth study of art theory, reading and appreciating literary and artistic works to improve their artistic accomplishment. In addition, the problem is exacerbated by the fact that strict requirements for correct and scientific anatomical structures impede students' emotional and personal development.

\section{References}

[1] Chen Hui: Talking About Teaching Basic Courses of Sculpture from Ilya Repin Institute of Arts. Art \& Design, October 2005, total 160. (in Chinese)

[2] Cao Chunsheng, Situ Zhaoguang. "The First All-Soviet Sculpture Exhibition and Others". World Art, 1984, No. 1. (in Chinese)

[3] Liu Kaiqu. Learning from Soviet Sculpture Art. Fine Arts, No.11, 1954. (in Chinese)

[4] Pan Yaochang, Ed. Chinese Art Education in the 20th Century, Shanghai Painting and Calligraphy Publishing House, 1999. (in Chinese)

[5] Shen Wenqiang. "The Age of Learning from Soviet Union", compiled by Zheng Chao, "Days of Sculpture - Seventy Years of the Sculpture Department of China Academy of Art", Hangzhou, China Academy of Art Press, April 1998. (in Chinese)

[6] Sun Zhenhua. A Review of the Century: A Brief Discussion on the Teaching of Sculpture in The Chinese Academy of Arts, Toward the Wasteland - Essays on Sculpture by Sun Zhenhua, Nanning, Guangxi Arts Publishing House, Co. February 1999. (in Chinese)

[7] Yin Shuangxi, Sui Jianguo, Ed. Time Travel: Selected Papers of Teachers in the Sculpture Department of the 80th Anniversary of the Central Academy of Fine Art, Xi 'an, Shaanxi People's Fine Arts Publishing House, 1998. (in Chinese)

[8] Zhang Wei, Zhou Simin, Chen Ke. "The Four Seasons such as Song: The Sculpture Department of Ilya Repin Leningrad Institute for Painting, Sculpture and Architecture", Beijing, People's Fine Arts Publishing House, June, 2004. (in Chinese)

Chen Hui: Talking About Teaching Basic Courses of Sculpture from Ilya Repin Institute of Arts. Art \& Design, October 2005 , total 160 , p. 80 